\title{
Sexo-política na literatura brasileira por mulheres
}

\author{
Gender, Discourse, and Desire in \\ Twentieth-Century Brazilian \\ Women's Literature.
}

FERREIRA-PINTO, Cristina.

West Lafayette: Purdue University Press, 2004. 208 p.

É de fôlego o estudo sobre narrativas escritas por mulheres de Cristina Ferreira-Pinto, seu mais recente trabalho depois do marcante O "Bildungsroman" feminino: quatro exemplos brasileiros (1990). No estudo, a autora enfoca a resposta contraideológica de escritoras. Enfatiza sua contestação em relação aos mitos femininos do cânone literário brasileiro através dos quais o discurso e o desejo masculinista terminaram por desfigurar e silenciar as mulheres. Precedido por uma abrangente crolonogia da atuação da mulher na sociedade brasileira e situação da produção literária de escritoras de 1752 a 2000, o livro é composto de uma introdução, seis capítulos e conclusão. Com trabalhos selecionados de escritoras várias, como Gilka Machado (1893-1980), Lygia Fagundes Telles (1923- ), Helena Parente Cunha (1930- ), Marina Colasanti (1937-), Lya Luft (1938-), Sônia Coutinho (1939- ), Myriam Campello (1948- ), Márcia Denser (1949-) e Marilene Felinto (1957-), sem deixar de passar pelo crivo de um pertinente elenco de teóricas feministas, o livro trata de questões de gênero no âmbito da individualidade. O âmago do estudo localiza nos discursos da sexualidade e do desejo das mulheres o delinear de sua identidade, que se plasma como literatura.

$\mathrm{Na}$ introdução, "A literatura das mulheres como discurso contra-ideológico", Ferreira-Pinto afirma que há de fato uma tradição de literatura escrita por mulheres, ainda que em maior volume a partir do século XIX e como profissão estabelecida apenas no século XX, embora escritoras que fizeram nome e carreira na linhagem literária brasileira a partir do século XX apareçam como "exceções isoladas e esporádicas". Ferreira-Pinto credita a Zahidé Lupinacci Muzart e seu imprescíndivel projeto de recuperação da obra de escritoras dos séculos XIX e anteriores a recuperação de tal tradição.

Anterior aos anos 1960, quando a produção literária da mulher se torna contundente na oposição ao patriarcalismo cultural brasileiro, ou "discurso dominate", a autora assinala, portanto, que já existiam obras que procuravam interferir na hegemonia dos mitos que aprisionaram as mulheres em papéis sociais, papéis estes que limitaram seu desejo em identidades e experiências enfatizadoras apenas da beleza, da juventude e da delicadeza como os atributos definidores da feminilidade. A autora propõe expor como a linguagem poética dos textos que analisa mostra-se expressão tanto de uma realidade que se altera como do discurso sobre esta.

Em "Corpo de mulher, desejo de homem", do Capítulo 1, a autora ilustra, com a produção literária escrita por homens, aspectos do "discurso dominante" ao qual se refere e o qual parece nortear a resposta das escritoras que analisa. Munida de conhecimento crítico nacional, com Antonio Candido, Dante Moreira Leite e Affonso Romano de Sant'Anna, e internacional, com Doris Sommer, Terry Eagleton, Michel Foucault e David Foster, para citar uns poucos, Ferreira-Pinto expõe celebrados mitos da literatura romântica e realista através de análises aptas. Mostra, por exemplo, como Iracema reúne em si a carga de papéis femininos como Eva, Maria e Pietá, com suas conotações de sensualidade e submissão, porém etnicamente marcada por sua origem indígena. Nas tramas de Memórias de um sargento de milícias, a autora apresenta a ideologia heterossexual voltada ao casamento 
e à reprodução como normas e o comportamento desviante da personagem Vidinha mulata sensual - como a baliza que sugere a ordem social como tal. Dialogando com a celebrada análise de Antonio Candido, que nos deu a "Dialética da malandragem" entre a ordem e a desordem, Ferreira-Pinto sugere a dialética que, de um lado, coloca a mulher doméstica e, de outro, a mulher pública, dicotomia esta formada por uma dialética conceitual entre raça e sexualidade que, enfim, nos legou aquilo que a autora ironicamente denomina como o mito da "mulata cordial". Rita Baiana d'O cortiço, claro, é mencionada como outro exemplo desse tipo, ao lado de outros estereótipos que servem de contraponto entre si: a lésbica Pombinha, a prostituta Leónie, as ninfomaníacas Estela e Leocádia, as reprodutoras Augusta e Piedade. Finalmente, considera as personagens de Machado de Assis aparentes ideais de feminilidade, mas de uma complexidade ímpar na literatura da época. As personagens, ainda assim, em seu julgamento, seguem os ditames das normas da vida doméstica, dentro do casamento e da vida urbana burguesa cujo alvo é a ascensão social.

No Capítulo 2, Ferreira-Pinto inicia o contradiscurso das mulheres, como propõe o título "Escritoras brasileiras: a busca de um discurso erótico". Após uma introdução que discute os trabalhos de escritoras do século XIX como pano de fundo, a autora mostra que Gilka Machado supera o comportamento "subserviente ao desejo masculino", pois expressa, em seu texto, os anseios do corpo da mulher. Ferreira-Pinto comenta que grande parte da crítica que se debruça sobre os estudos de gênero na literatura considera a obra de Gilka Machado como aquela que inaugura a Erótica que a autora focaliza entre as escritoras selecionadas para seu estudo. Usando elementos teóricos de críticas como Hélène Cixous, Luce Irigaray e Teresa de Lauretis, a autora dá vivacidade à temática da escritora carioca e nos revela uma criadora forte e contemporânea. Uma discussão que procura situar o discurso erótico feminino distinguindo-o do texto pornográfico e do eroticismo pronunciado por personagens mulheres em textos escritos por homens, que terminam por endossar a "ideologia dominante masculinista" - é seguida da análise do erotismo como uma forma de reestruturar a identidade das protagonistas em $A$ mulher no espelho, de Helena Parente Cunha, e em As mulheres de Tijucopapo, de Marilene Felinto. A autora procede a uma análise minuciosa desses textos, tendo como ponto de vista fundamental o fato de que os trabalhos opõem a pulsão do desejo do macho adulto branco, que por muito tempo embasou as relações sociais no Brasil, ao menos no âmbito das elites.

As obras Quarto fechado, de Lya Luft, e As horas nuas, de Lygia Fagundes Telles, são enfocadas no Capítulo 3, "A representação do corpo feminino e o desejo: o gótico, o fantástico e o grotesco". Nesse capítulo, Ferreira-Pinto envereda por uma visão inovadora das obras, quando considera os gêneros gótico, fantástico e grotesco como uma estratégia através da qual as escritoras comunicam o constrangimento e o deslocamento das protagonistas diante do ambiente patriarcal que as cerca e ainda cerceia. Outro tema crescentemente relevante, mas explorado há apenas poucas décadas, especialmente como atributo crucial da feminilidade, compõe o Capítulo 4, "O conto de Sônia Coutinho: o envelhecimento e o corpo da mulher". A autora do estudo mostra como Coutinho expressa a decepção da protagonista quando esta verifica, surpresa, sua inabilidade de seduzir homens, quando percebe que os cosméticos não trarão de volta a beleza perdida com os anos e o fato consequente de que, para a mulher, o tornar-se idosa significa um progressivo descrédito como pessoa por causa da perda gradual de seu apelo sexual, também por não mais possuir a capacidade reprodutora. Ao mesmo tempo, o texto de Coutinho sugere que a fruição plena da sexualidade da mulher é possível apenas se ela transcender os mitos de feminilidade apresentados a ela como o curso natural das coisas pelo "discurso dominante". Só assim pode a mulher se desvencilhar dos parâmetros de adequação, segundo os quais teria que "agir de acordo com sua idade", e então ser livre para viver, sem as imposições que limitam sua existência a papéis prescritos por outrem.

No Capítulo 5, "O conto brasileiro contemporâneo escrito por mulheres: o desejo lésbico", após oferecer um histórico que mostra o modo como a homossexualidade masculina e a feminina foram constituídas pelo discurso das instituições normativas, estando entre estas principalmente a Igreja, a autora mostra como diferentes teóricos (David Foster, Gloria Anzaldúa, Ronaldo Vainfas, Luís Mott, entre outros) trataram o assunto e como os temas queer foram expressos na literatura brasileira do século XX. Trabalhos de Edla Van Steen, Sônia Coutinho, Lygia Fagundes Telles, Myriam Campello e Márcia Denser são analisados tendo-se em conta a 
diversidade com que tratam do desejo lésbico, um espaço de transgressão e agência da muIher que desse modo se afirma livre como sujeito.

"Os trabalhos de Márcia Denser e Marina Colasanti: a agência feminina e a heterossexualidade" mostra que, mesmo apresentando protagonistas heterossexuais, as escritoras que - Capítulo 6 analisa assumem, muita vez, uma posição de confronto vis-à-vis ao patriarcalismo, o que as alinha politicamente com as escritoras que se expressam através do desejo lésbico. Com sua "ficção sexual", para além da dicotomia entre erótico e pornográfico, Denser, segundo a autora, desestabiliza as convenções de gênero, assim promovendo a afirmação da sexualidade da protagonista, que demonstra um grande apetite sexual, o que não é comumente caracterizado como atributo de mulher "de bem" na literatura. Colasanti, por seu turno, se expressa através de um "erotismo do corpo" que afirma a mulher como tal - sem o costumeiro pejo com que somos ensinadas a disfarçar funções orgânicas. Ferreira-Pinto observa que, não se atendo ao lirismo e usando termos considerados de baixo calão, Colasanti se apodera das palavras usualmente pronunciadas pelos homens e, paradoxalmente, afirma a agência da mulher.

$\mathrm{Na}$ Conclusão, "Escritoras brasileiras no novo milênio", Ferreira-Pinto reitera sua observação de que, sendo a sexualidade aquilo que define a identidade da pessoa, o desejo (erótico, homossexual, heterossexual etc.), que necessariamente expressa tal sexualidade, aborda de frente o princípio criativo das escritoras. Desse modo, o desejo que se faz texto expressa a identidade ou posição da escritora - poderíamos denominar tal posicionamento sua sexopolítica -, seguindo a vereda aberta pelo importante estudo de Kate Millett, o clássico Sexual Politics?

Como fica claro, este é um estudo que, embora panorâmico, utiliza um bom arsenal teórico para examinar algumas de nossas melhores escritoras. Em inglês, é ao mesmo tempo uma imprescindível apresentação das escritoras no âmbito de Women's Studies na literatura brasileira e um estudo bastante útil nas salas de aula no campo Brazilian Studies dos Estados Unidos, onde tais análises são escassas, mas muito necessárias. No sentido de instigar Brazilianistas ainda mais em relação ao assunto, no entanto, teria sido interessante ver esmiuçadas algumas generalizações no decorrer do texto ("o discurso dominante masculinista", "a mulher", "a sociedade brasileira patriarcal e eurocêntrica", "algumas mudanças sociais e políticas importantes [a partir de 1970]" etc.) e ter obtido um tratamento mais complexo à relação, central no estudo, entre sexualidade, desejo, identidade e formação discursiva, pontos que, embora sejam apresentados como subentendidos a estudiosos do assunto, por isso mesmo detêm, na chance única que a publicação do livro apresenta, a consideração de novos prismas na revisitação de velhos problemas.

Regina R. Félix University of North Carolina Wilmington 